\title{
Las obligaciones de resultado atenuadas: una posible solución al conflicto entre igualdad y equidad en el contrato de transporte benévolo
}

DOI: http://dx.doi.org/10.15425/2017.516

\section{Resumen}

El transporte benévolo ha suscitado diversas discusiones jurídicas en razón al tipo de responsabilidad civil que surge de este. La corriente anticontractualista afirma que dicho transporte solo es una relación social que no produce efectos jurídicos. Por otro lado, la corriente contractualista sostiene que existe un contrato de transporte benévolo que vincula jurídicamente al transportador con quien le solicita dicho servicio. Como consecuencia de tal reconocimiento, las obligaciones en cabeza del transportador benévolo son tomadas de las obligaciones propias del contrato de transporte oneroso puesto que es el contrato regulado más próximo al que se estudia en este documento. El uso de la analogía para hacer efectivas estas obligaciones ocasiona un conflicto entre la posición de las víctimas y la de los transportadores en cada uno de los contratos. Por tal razón, se propone la utilización de la categoría de las obligaciones de resultado atenuadas para dirimir tal confrontación.

\section{Palabras claves}

Responsabilidad civil, transporte benévolo, obligaciones de resultado atenuadas.

\footnotetext{
Abogado de la Pontificia Universidad Javeriana (2011). Especialista en derecho comercial de la Universidad de los Andes (2014). Magíster en derecho privado de la Universidad de los Andes (2016). Especialista en derecho financiero y bursátil de la Universidad Externado de Colombia (2020). Profesor del Departamento de Derecho Privado de la Pontificia Universidad Javeriana. Correo electrónico: apadillatamara@gmail.com.
} 


\title{
Obligations of attenuated result: A possible solution to conflict between equality and equity in gratuitous carriage contract
}

\begin{abstract}
Gratuitous carriage contract has raised several legal arguments due to the type of liability arising from it. Firstly, there is a position, identified as non-contract theory, which states that such carriage is only a social relationship that has no legal effect. However, on the other hand, there is a theory that maintains the existence of a type of agreement denominated gratuitous carriage contract which is binding to carriers. As a result of such recognition, carriers have obligations which are taken from onerous carriage contract regulation since it is the most similar regulated contract to the studied agreement on the understanding that both of them have common elements. The analogy used about these obligations causes a conflict between the legal treatment of casualties and carriers in each of the announced contracts. For this reason, the study of obligation of attenuated results would solve the situation pointed out previously.
\end{abstract}

\section{Keywords}

Liability, gratuitous carriage, obligation of attenuated result. 


\section{Introducción}

Los conflictos derivados del transporte benévolo generan álgidas discusiones dentro del derecho de daños, tanto en la doctrina nacional como en la extranjera, puesto que su naturaleza jurídica se debate entre la responsabilidad civil contractual y la extracontractual. La importancia de la determinación de la responsabilidad surgida por el daño ocasionado en el marco de la mencionada relación jurídica cobra importancia desde dos puntos de vista. Bajo la responsabilidad contractual, la víctima queda suficientemente protegida puesto que no debe probar la culpa para reclamar la indemnización por el incumplimiento de la obligación de transportarla de manera segura, mientras que, en la responsabilidad civil extracontractual, de acuerdo con la jurisprudencia civil tradicional, la víctima queda en una posición desventajosa, dado que se requiere de la prueba de todos los elementos de la responsabilidad para demandar la reparación del daño sufrido, creándose de esta manera una posible violación al principio de igualdad. Por otro lado, la segunda perspectiva en la que puede analizarse el tema que nos ocupa tiene como eje el principio de justicia, puesto que, el transportador benévolo, además de no recibir contraprestación por el servicio que presta, no tiene en la responsabilidad contractual más medios de defensa que los que tiene el transportador a título oneroso, los cuales, como es suficientemente conocido, se restringen a la prueba del factor extraño para efectos de desvirtuar la relación de causalidad.

Para conciliar los principios de igualdad y equidad dentro de la corriente contractualista, antes del estudio de las posiciones doctrinales al respecto, se propone la adopción de una categorización nueva de las obligaciones de resultado, para que (1) la víctima sea beneficiaria de la presunción de culpa propia de las obligaciones de resultado y se releve de la demostración de dicho elemento en el marco de la responsabilidad civil, y (2) el transportador benévolo pueda acudir a los distintos medios de defensa, estructurados para las obligaciones de medios, como la debida diligencia, sin necesidad de sacrificar la naturaleza de resultado de la obligación de la cual es acreedora la víctima ${ }^{1}$.

$1 \quad$ Conforme se expondrá en el documento, son dos las principales diferencias entre las obligaciones de resultado y de medios. En primer lugar, en aquellas se presume la culpa en el incumplimiento de la prestación mientras que, en las denominadas obligaciones de medios, es el acreedor, demandante quien debe entrar a probar dicha falta de diligencia. Así mismo, en segundo lugar, los medios de defensa son distintos. Por un lado, las obligaciones de resultado sólo son admisibles las causas extrañas (fuerza mayor, hecho exclusivo de la víctima y hecho exclusivo de un tercero) mientras que, en las obligaciones de medios, se incluye, además de las causas extrañas, la debida diligencia. 
Por lo tanto, el estudio del transporte benévolo tiene como preámbulo el análisis sobre la tipicidad del contrato de transporte oneroso, pasando luego al transporte benévolo o de cortesía y las distintas corrientes doctrinales existentes al respecto, para finalizar en la propuesta comentada que buscaría dar solución al problema jurídico planteado.

\section{El contrato de transporte y su regulación en Colombia}

\section{A) Precisiones preliminares}

El contrato de transporte debe estudiarse desde la órbita civil y comercial en el ordenamiento jurídico colombiano. En cuanto al primer ordenamiento, debe recordarse que este contrato se ubica en el capítulo del contrato arrendamiento del Código Civil. El contrato de arrendamiento de transporte es definido como "un contrato en que una parte se compromete, mediante cierto flete o precio, a transportar o hacer transportar una persona o cosa de un paraje a otro" ${ }^{2}$. Por otro lado, desde el escenario mercantil, el transporte "es un contrato por medio del cual una de las partes se obliga con la otra, a cambio de un precio, a conducir de un lugar a otro, por determinado medio y en el plazo fijado, personas o cosas y entregar estas al destinatario"3. Así las cosas, podemos precisar que, si bien las definiciones del contrato de transporte son similares en ambos regímenes jurídicos, la diferencia radica en el ámbito de aplicación puesto que las disposiciones del Código de Comercio son las llamadas a regular el transporte como acto de comercio mientras que, por otro lado, el Código Civil se aplica en aquellos casos en los cuales las partes no son comerciantes, ni el transporte es ejecutado como un acto de comercio.

Por lo tanto, cuando se haga referencia al contrato de transporte, no se hará distinción entre el transporte civil y el comercial puesto que, tal como se demostrará en las líneas siguientes, los elementos esenciales son iguales en cada uno de ellos, así como las obligaciones a cargo de cada una de las partes.

2 Ley 84 de 1873, del 26 de mayo. Código Civil de la República de Colombia. Artículo 2070. Diario Oficial n. 2867 .

3 Decreto 410 de 1971, del 27 de marzo. Código de Comercio de la República de Colombia. Artículo 981. Diario Oficial n. 33339. 


\section{B) Definición del contrato de transporte}

Como es suficientemente conocido, el contrato es un acuerdo de voluntades mediante el cual dos o más personas manifiestan su voluntad, consciente y reflexivamente, con la finalidad de producir efectos jurídicos ${ }^{4}$.

Así mismo, para que las personas se obliguen entre sí en el marco de un contrato, es necesario que sean legalmente capaces, que manifiesten su consentimiento en el contenido del contrato y que este no adolezca de vicio, que su objeto sea lícito y la causa del contrato sea igualmente lícita ${ }^{5}$. Cumplidos los requisitos precisados como fundamentales para la existencia del contrato, debe proseguirse puntualmente con el contrato de transporte.

Tal como quedó precisado en líneas anteriores, dada la dicotomía entre régimen civil y comercial dentro del derecho privado colombiano, tanto el Código Civil como el Estatuto Mercantil tienen una definición propia del contrato de transporte, aun cuando esencialmente contienen los mismos elementos.

Ahora bien, una definición común a los regímenes comentados es aquella que nos indica que el transporte es "un convenio por el cual, una persona llamada transportador o transportista se obliga, a cambio de un precio, que se denomina flete o porte, a conducir de un lugar a otro, personas o cosas"6.

Por otro lado, es necesario puntualizar el alcance de las obligaciones de cada una de las partes que intervienen en el contrato. Para ello, debemos entender que "el que asume la obligación de transportar se denomina transportador o portado; remitente es la parte que solicita el transporte, que también puede ser destinatario o consignatario cuando es la persona a la que se ha de entregar las cosas, siempre que sean estas el objeto del contrato; pero cuando el destinatario es un tercero, se convierte en un elemento personal del transporte" ${ }^{\prime 7,8}$.

El Código Civil, en su artículo 1495, define el contrato como "es un acto por el cual una parte se obliga para con otra a dar, hacer o no hacer alguna cosa. Cada parte puede ser de una o de muchas personas".

5 Artículo 1502 del Código Civil precisa que "para que una persona se obligue a otra por un acto o declaración de voluntad, es necesario: 1. $^{\circ}$ ) que sea legalmente capaz. $2 .^{\circ}$ ) que consienta en dicho acto o declaración y su consentimiento no adolezca de vicio. $3 .^{\circ}$ ) que recaiga sobre un objeto lícito. $\left.4 .^{\circ}\right)$ que tenga una causa lícita. La capacidad legal de una persona consiste en poderse obligar por sí misma, sin el ministerio o la autorización de otra.

6 Jaime Alberto Arrubla Paucar, Contratos mercantiles (Bogotá: Ediciones Diké, 1988), 245.

7 José Alejandro Bonivento Fernández, Los principales contratos civiles y comerciales. Tomo II (Bogotá: Ediciones Librería del Profesional, 1991), 168.

8 El artículo 2070 del Código Civil establece que "El que se encarga de transportar se llama generalmente acarreador, y toma los nombres de arriero, carretero, barquero, naviero, según el modo de hacer el transporte. El que ejerce la industria de hacer ejecutar transportes de personas o cargas, se 


\section{C) Características}

Resulta de vital importancia, para efectos del estudio del contrato de transporte, la determinación de las características propias de este negocio jurídico. Para esto debo precisar que el contrato de transporte es consensual,conmutativo, nominado, principal y oneroso.

- Consensual: un contrato "es consensual cuando se perfecciona por el solo consentimiento" 9 . Es así que se concluye que el contrato de transporte es consensual puesto que "se perfecciona por el solo acuerdo de las partes"10. Desde la perspectiva procesal, esta característica presenta ventajas en cuanto a la libertad probatoria que tienen las partes para demostrar la existencia del contrato conforme a las reglas del Código General del Proceso.

- Conmutativo: el contrato de transporte es un contrato conmutativo puesto que tanto transportador como quien contrata el servicio de transporte "se obliga[n] a dar o hacer una cosa que se mira como equivalente a lo que la otra parte debe dar o hacer a su vez"11.

- Nominado: por encontrarse reglamentado en el ordenamiento jurídico colombiano, el contrato de transporte es un contrato nominado. Este tipo de contratos "son los que tienen un nombre y están reglamentados por la ley"12.

- Principal: "esta clasificación se hace atendiendo a la manera como los contratos existen"13 . En el régimen colombiano, "el contrato es principal cuando subsiste por sí mismo sin necesidad de otra convención"14. Es decir, el transporte, como acto jurídico, nace y subsiste en el tráfico

llama empresario de transportes. La persona que envía o despacha la carga se llama consignante, y la persona a quien se envía consignatario".

Ley 84 de 1873, del 26 de mayo. Código Civil de la República de Colombia. Artículo 1500. Diario Oficial n. 2867 .

10 Decreto 410 de 1971, del 27 de marzo. Código de Comercio de la República de Colombia. Artículo 981. Diario Oficial n. ${ }^{\circ} 33339$.

11 Ley 84 de 1873, del 26 de mayo. Código Civil de la República de Colombia. Artículo 1498. Diario Oficial n. ${ }^{\circ} 2867$.

12 Arturo Alessandri Rodríguez, Derecho civil de los contratos (Santiago de Chile: Ediciones Zamorano y Caperan, 1976) 11. Ibid.

14 Ley 84 de 1873, del 26 de mayo. Código Civil de la República de Colombia. Artículo 1499. Diario Oficial n. 2867. 
jurídico sin que sea necesaria la existencia de otro contrato al cual le debería acceder.

- $\quad$ Oneroso: el contrato de transporte es oneroso puesto que reporta utilidad a ambos contratantes.

\section{D) Obligaciones principales surgidas en virtud del contrato de transporte}

Las obligaciones principales que surgen para las partes del contrato de transporte son, para el transportador o transportista, la de conducir a las personas y cosas transportadas de manera segura, conforme a lo pactado, y para quien contrata el transporte, la de pagar el flete o precio del transporte.

Conforme a lo anterior, debemos precisar que la obligación de pagar el flete o precio del transporte, catalogada comúnmente entre las obligaciones genéricas de dar ${ }^{15}$, es considerada una obligación de resultado. Al efecto es importante precisar que "la mayor parte de los autores considera que la obligación de dar, por su propia naturaleza, determina siempre una prestación de resultado, ya que solo se cumple con la obtención del resultado jurídico consistente en el cambio posesorio"16, en nuestro caso, la transferencia del dinero de quien contrata el servicio al transportador.

Por otro lado, el contrato de transporte, tanto desde la óptica civil como comercial, genera la obligación, en cabeza del transportador, de conducir a las personas y cosas transportadas "dentro del término por el modo de transporte y la clase de vehículos previstos en el contrato y, en defecto de estipulación, conforme a los horarios, itinerarios y demás normas"17. Esta obligación, catalogada dentro de las obligaciones de resultado ${ }^{18}$ da lugar a que el transportador garantice la ejecución de la prestación contenida en ella de manera tal que solo el resultado ofrecido

15 " $[. .$.$] las obligaciones de dar normalmente se cumplen mediante la entrega material de las cosas$ que constituyen su objeto, tal entrega comprende en esta clase de obligaciones la intención específica que las partes abrigan al hacerla: la de producir la mutación en el dominio de dichas cosas". Guillermo Ospina Fernández, Régimen general de las obligaciones (Bogotá: Temis, 1978), 300.

16 Antonio Cabanillas Sánchez, Las obligaciones de actividad y de resultado (Barcelona: Ediciones José María Bosch, 1993), 48.

17 Decreto 410 de 1971, del 27 de marzo. Código de Comercio de la República de Colombia. Artículo 982. Diario Oficial n. ${ }^{\circ} 33339$.

18 Estas obligaciones son creadas en Francia a través de la doctrina. René Demogue, Traité des Obligations en Général, tomo V (París: Librairie Arthur Rousseau et Cie., 14, Rue Soufflot, 14, 1925) con la finalidad de resolver el problema de la carga de la prueba en el incumplimiento de las obligaciones dentro del ámbito contractual. Dicho aspecto, contrario a lo que sucede en derecho colombiano $y$, en general, en los ordenamientos jurídicos latinoamericanos donde los legisladores nacionales solucionaron el problema, ha sido resuelto en Francia a través del desarrollo de la doctrina. 
satisfaría el interés jurídico del acreedor en el mismo, es decir, conducir, de manera segura, las cosas y personas de acuerdo con lo convenido ${ }^{19}$. Ante el incumplimiento de esta obligación, el transportador solo, de acuerdo con la Sala de Casación Civil de la Corte Suprema de Justicia, en sentencia del 16 de diciembre del 2010: "podría eximirse [...] demostrando la concurrencia de alguno de los acontecimientos que dependen de lo que se ha denominado una causa extraña"20.

Al respecto debemos precisar que las obligaciones de resultado son aquellas en las cuales el deudor asume el compromiso de que se materialice u obtenga el resultado, logro o finalidad pactados en el contrato. Dichos logros o resultados específicos, ha establecido la Corte Suprema de Justicia, en sentencia del 30 de noviembre de 1935, que son aquellos "actos que el deudor debe ejecutar [y] están estrictamente indicados en el contrato o en la ley supletiva"21. Ante el incumplimiento de estas obligaciones, el deudor es el llamado a demostrar una de las tres causas extrañas ${ }^{22}$ que rompen la relación de causalidad entre el hecho y el daño, como consecuencia de ello, pueda eximirse de responsabilidad.

También, es importante puntualizar que existe un deber de protección u obligación de seguridad inmersa en la prestación a cargo del transportador. El deber de seguridad, enmarcado dentro de los deberes secundarios de conducta, podría definirse como aquel que recae "sobre el deudor de una prestación principal y cuyo objeto consiste en evitar que sean lesionados intereses personales o patrimoniales de la contraparte"23. En el caso del contrato de transporte, "el deudor (transportador) se obliga [no solo] a trasladar personas y cosas de un lado a otro (deber de prestación principal), sino también a que lleguen incólumes al lugar de destino

La tesis de Sarrut terminó por imponerse, y fue así como la Corte de Casación, aceptando la responsabilidad contractual del transportador, declaró a su cargo la obligación de transportar al viajero sano y salvo a destino, debiendo, en caso de accidente, probar que la inejecución de su obligación depende de una causa extraña que no puede serle imputada". Arturo Acuña Anzorena, "Transporte gratuito y responsabilidad en caso de accidente", en Responsabilidad civil. Doctrinas esenciales (parte especial) tomo IV, ed./comp. Félix Trigo (Buenos Aires: La Ley, 2007), 337.

20 Corte Suprema de Justicia. Sala de Casación Civil. Sentencia de 16 de diciembre del 2010. M. P. Arturo Solarte Rodríguez.

21 Corte Suprema de Justicia. Sala de Casación Civil. Sentencia de 30 de noviembre de 1935. M. P. Eduardo Zuleta.

22 "La causa extraña está constituida por la fuerza mayor o caso fortuito, por el hecho de un tercero, o por el hecho de la víctima. Conviene resaltar igualmente que la fuerza mayor, así como los otros casos de causas extrañas, son considerados como ruptura del vínculo causal entre la conducta del agente y el daño sufrido por la víctima". Javier Tamayo Jaramillo, Tratado de responsabilidad civil (Bogotá: Legis, 1986), 315. Universitas 53, n. 108 (2004): 307. https://revistas.javeriana.edu.co/index.php/vnijuri/article/ view/14730 
(deber de protección u obligación de seguridad)"24. Esta obligación de seguridad, en principio explicable en virtud del principio de ejecución de buena fe, está plasmada legislativamente en Colombia en la disposición establecida en el artículo 982 del Código de Comercio.

\section{E) Elementos del contrato de transporte}

De acuerdo con el Código Civil colombiano, los elementos de los contratos son los siguientes ${ }^{25}$ : elementos esenciales del contrato, elementos de la naturaleza del contrato y elementos accidentales del contrato.

\section{Los elementos esenciales del contrato de transporte}

Los elementos esenciales de los contratos pueden definirse como aquellos que "constituyen lo mínimo que las partes deben declarar para precisar el interés que pretenden desarrollar jurídicamente y el sentido en que quieren hacerlo"26. Es decir, estos elementos se erigen como fundamentales en el momento de la estructuración del negocio jurídico, puesto que, ante la ausencia de alguno de ellos, el contrato deseado no existe o degenera en otro ${ }^{27}$.

La remuneración, presente en la definición del contrato de transporte tanto en el régimen civil como en el comercial, constituye un elemento esencial de este específico negocio jurídico. Este elemento está representado en la contraprestación a título de flete o precio que se obliga a pagar quien contrata el transporte, es decir, el remitente. A cambio del precio pagado por el remitente se realiza el servicio contratado, en beneficio del mismo remitente o del destinatario designado.

El artículo 1501 del Código Civil establece que "se distinguen en cada contrato las cosas que son de su esencia, las que son de su naturaleza, y las puramente accidentales. Son de la esencia de un contrato aquellas cosas sin las cuales, o no produce efecto alguno, o degeneran en otro contrato diferente; son de la naturaleza de un contrato las que, no siendo esenciales en él, se entienden pertenecerle, sin necesidad de una cláusula especial; y son accidentales a un contrato aquellas que ni esencial ni naturalmente le pertenecen, y que se le agregan por medio de cláusulas especiales". dico (Bogotá: Ediciones Temis, 2005), 36.

De acuerdo con el artículo 1501 del Código Civil dispone que son elementos de "la esencia de un contrato aquellas cosas sin las cuales, o no produce efecto alguno, o degeneran en otro contrato diferente". 
Por otro lado, la conducción o transporte de personas o cosas de un lugar a otro constituye el otro elemento esencial, puesto que la existencia de esta actividad es el pilar fundamental del contrato de transporte y su función económico-social.

La inexistencia de la obligación de trasladar cosas o personas en cabeza del transportador o de la contraprestación a cargo de quien contrata el transporte generaría la inexistencia de una relación jurídica encuadrada en el contrato de transporte y, podría generar, la existencia de una donación o un pago de lo no debido, en el primero de los casos. En el segundo de los supuestos, cuando estamos frente a la inexistencia de la remuneración, se generaría un tipo de transporte distinto, conocido como transporte benévolo o gratuito.

\section{Los elementos de la naturaleza del contrato de transporte}

El Código Civil colombiano hace referencia a los elementos de la naturaleza del contrato, definiéndolos como aquellos "que no siendo esenciales en él, se entienden pertenecerle, sin necesidad de una cláusula especial"28. Por lo tanto, estos elementos son aquellos en los que el mismo ordenamiento jurídico establece el contenido básico del negocio, y, en consecuencia, suple la voluntad de las partes cuando ellas no se han pronunciado respecto de uno o varios aspectos del contrato de manera específica. Un ejemplo de este tipo de elementos puede encontrarse en el artículo 982 del Código de Comercio que establece que "[e]l transportador estará obligado, dentro del término por el modo de transporte y la clase de vehículos previstos en el contrato y, en defecto de estipulación, conforme a los horarios, itinerarios y demás normas contenidas en los reglamentos oficiales" ${ }^{29}$. El mencionado artículo deja en libertad a las partes de pactar en el contrato los aspectos enunciados, sin embargo, a falta de pacto expreso en la convención, el mismo artículo los regula.

\section{Los elementos accidentales del contrato de transporte}

Estos elementos del contrato son aquellos que, sin ser esenciales o de la naturaleza, son acordados expresamente por las partes mediante la incorporación de cláusulas especiales en el texto del contrato. Dentro de este tipo de elementos podemos encontrar las condiciones, plazos y penalidades que pactaren las partes. Oficial n. 2867 .

29 Decreto 410 de 1971, del 27 de marzo. Código de Comercio de la República de Colombia. Artículo 982. Diario Oficial n. ${ }^{\circ} 33339$. 


\section{F) El transporte benévolo}

Como consecuencia de la inexistencia del elemento esencial de la onerosidad del contrato típico de transporte, regulado tanto en el Código Civil como en el Código de Comercio, se plantea como una relación distinta el transporte benévolo o de cortesía, el cual es definido como aquella relación que surge "cuando la conducción de personas o cosas se hace sin remuneración alguna y sin que acceda a un acto de comercio, como por ejemplo, el que lleva a una persona de un lugar a otro sin mediar prestación alguna, o sea, por plena liberalidad, bien por acto accidental o en forma periódica"30.

\section{El transporte benévolo, su naturaleza, características y sistema de responsabilidad civil}

\section{A) Naturaleza}

Como se ha señalado, el transporte benévolo es aquella relación jurídica en virtud de la cual, sin existir remuneración alguna por el servicio y sin ser accesorio a un acto de comercio, una persona, denominada transportador benévolo, conduce personas o cosas de un lugar a otro.

Así mismo, puede definirse el transporte benévolo como aquella relación en la que "el conductor, dueño o guardián del vehículo invita o consiente llevar a otra persona, por acto de mera cortesía o con la intención de hacer un favor, sin que el viajero o un tercero se encuentren obligados a efectuar retribución alguna por el transporte" ${ }^{\prime 3}$.

No obstante la definición anterior, se entiende que el transporte benévolo no es únicamente aplicable a la conducción de personas, sino también de cosas puesto que no existen elementos objetivos para diferenciar el régimen aplicable de uno y otro ${ }^{32}$.

Marcelo López Mesa, "Responsabilidad derivada del transporte benévolo de personas", en Tratado de responsabilidad civil, tomo IV, ed./comp. Félix Trigo y Marcelo López (Buenos Aires: La Ley, 2011), 533. 
Alrededor de la naturaleza de este tipo de relación jurídica, la doctrina nacional y extranjera ha creado dos corrientes de pensamiento. La primera, conocida como la corriente anticontractualista, cree que el transporte benévolo no debe ser considerado un contrato puesto que carece de la intención de las partes en obligarse jurídicamente como elemento para su existencia. Por otro lado, la corriente contractualista estudia este mismo fenómeno jurídico desde la óptica general del negocio jurídico, en virtud de la cual concluye que cuando el transporte se conviene de ese modo se da origen a un contrato atípico.

Que el intérprete se ubique en una u otra tesis tiene implicaciones importantes en la medida en que hay consecuencias importantes en temas tales como el tipo de obligación asumida por el transportador, la carga de la prueba de los presupuestos de la responsabilidad civil y el régimen de responsabilidad civil aplicable a la situación.

\section{La corriente anticontractualista}

La corriente anticontractualista ${ }^{33}$ precisa que

el conductor al invitar o aceptar el pedido del pasajero, no tiene la intención de obligarse de ninguna forma con él; y así aquel puede libremente invitarlo a descender, alterar o suspender el viaje, y a tomar todas las disposiciones sin hallarse limitado en ninguna forma por la presencia de su acompañante ${ }^{34}$.

Por tal razón, "debe descartarse la naturaleza contractual de la responsabilidad derivada de un transportador benévolo. Ello por la sencilla razón de que no existe un 'contrato de transporte benévolo' y sin contrato, no puede conceptualmente existir responsabilidad contractual" ${ }^{\prime 35}$. Así mismo, se ha afirmado, en el estudio de un caso de transporte benévolo, que "[I]a relación jurídica trabada entre un conductor y la actora encuadra en un típico transporte benévolo que determina la responsabilidad de aquel en el marco extracontractual" ${ }^{\prime 36}$.

"El transporte benévolo se ubica (para la doctrina mayoritaria) claramente en el sistema de responsabilidad civil, consagrado a partir del artículo 1113 del Código Civil [Argentino], independientemente de algunas posturas minoritarias en doctrina y jurisprudencia, que lo colocan en el ámbito de la responsabilidad contractual". Mosset y Piedecasas, Accidentes de tránsito, 227. 1983), 144. 
En ese sentido, la Corte Suprema de Justicia de Colombia expresó que

[e]n el transporte gratuito, caracterizado por el móvil desinteresado que anima al conductor y originado por la "relación mundana", por la mera cortesía del que lo realiza, no se reúnen los requisitos anotados, por lo cual se aparta de la clasificación ante dicha ${ }^{37}$.

Para tales efectos,

"Messineo afirma, en relación con el derecho italiano que, "afirmada la naturaleza no-contractual de transporte (de personas) amigable o por cortesía, de ello se deduce excluida, por tanto, una responsabilidad contractual, por daño a la persona del transportado [pero], no por eso se puede dejar indefenso a este último. La jurisprudencia ha considerado que debe recurrirse a los principios de la responsabilidad aquiliana" ${ }^{38}$.

No obstante la autoridad de los mencionados autores, es necesario precisar que la relación intrínseca al transporte benévolo debe dotársele de entidad jurídica desde el inicio de la relación, puesto que ninguna interacción social puede estar por fuera del derecho. Por lo tanto, al señalarse que la responsabilidad civil surgida del daño ocasionado en el marco del transporte benévolo es de carácter extracontractual, se está menospreciando el vínculo jurídico previo al daño constituido en el momento de celebración y ejecución del transporte por cortesía.

En ese sentido, la corriente contractualista ha puesto de presente que

[e]l carácter contractual del transporte gratuito se transparenta en el acuerdo de voluntades sobre la conducción, solicitada, ofrecida, impuesta por una conveniencia social, etc. El transportador tiene la libertad de no transportar, de no entrar en relaciones con el pasajero y sólo ahí existe un signo de que ha tenido lugar el acuerdo referido por el contrato ${ }^{39}$.

Corte Suprema de Justicia. Sala de Negocios Generales. Sentencia de 11 de febrero de 1946. M. P. Eleuterio Serna. 
La corriente contractualista

La corriente contractualista ${ }^{40}$ considera que existe un contrato atípico ${ }^{41}$ en la relación jurídica subyacente en el transporte benévolo y, como consecuencia, con la virtualidad de producir obligaciones en cabeza de cada una de las partes intervinientes, dado que "[I] a benevolencia, la complacencia, o la gratuidad no son obstáculos para que se forme un contrato. [...] Y la conciencia de contratar o animus negotti contrahendi, real no presumida, no es requisito inexcusable" ${ }^{\prime 2,43}$.

Al respecto debe tenerse presente que, desde la óptica legal colombiana, el Código Civil dispone que

[p]ara que una persona se obligue a otra por un acto o declaración de voluntad, es necesario: $1 .^{\circ}$ ) Que sea legalmente capaz. $2^{\circ}$ ) que consienta en dicho acto o declaración y su consentimiento no adolezca de vicio. $3 .^{\circ}$ ) que recaiga sobre un objeto lícito. $\left.4 .^{\circ}\right)$ que tenga una causa lícita ${ }^{44}$.

"Para Savatier, el transporte gratuito como el oneroso, es un verdadero contrato. Como otros contratos que implican un servicio gratuito, por ejemplo, el mandato — del que no difiere más que por el carácter de dicho servicio- puede sin duda ser rescindido ad nutum, por una u otra parte. Ello no impide que las obligaciones derivadas de este transporte sean contractuales y esto es así en virtud de una convención tácita por la que el transportador obliga a velar por la seguridad de la persona transportada, como así también a no abandonarla en medio de una ruta, lejos de todo auxilio" (Beatriz Areán. "La responsabilidad civil y el transporte benévolo", en Responsabilidad civil. Doctrinas esenciales (parte especial) tomo IV, ed./comp. Félix Trigo (Buenos Aires: La Ley, 2007), 373.

Así mismo, se puntualiza que "Lalou, menos concluyente a este respecto, sostiene que la gratuidad del transporte no excluye necesariamente el contrato, como la ausencia de precio en una convención de dación no lo excluye tampoco. Para Lalou, entre el transporte oneroso y el gratuito existe la misma diferencia que entre la venta y la donación, pero, en ambos casos hay contrato". Acuña, "Transporte gratuito y responsabilidad en caso de accidente", 339.

41 "Nada obsta a la existencia de un contrato civil atípico de transporte gratuito, si bien reconocemos que la onerosidad es esencial en el contrato comercial de transporte [...] Obsérvese que la falta de un interés económico del transportista no es obstáculo a la índole contractual de la relación [...]”. Jorge Mosset, Responsabilidad por daños. Tomo I (Buenos Aires: Ediar, 1979), 340.

42 Jorge Mosset, “¿El transportado gratuitamente viaja a riesgo y ventura? (La asunción o aceptación del riesgo como falacia jurídica)", en Responsabilidad civil doctrinas esenciales (parte especial) tomo IV, ed./comp. Félix Trigo (Buenos Aires: La Ley, 2011), 400.

"Obsérvese que la falta de un interés económico en el transportista no es obstáculo a la índole contractual de la relación, pues son contratos desinteresados, las liberalidades, la donación, el mandato gratuito, el comodato. Y, por lo demás, es innegable que la prestación de hacer - traslado del pasajero- tiene contenido patrimonial. También en el comodato, préstamo gratuito de una cosa con facultad de usarla, puede mediar un acto de cortesía, el deseo de hacer un favor al comodatario, y el comodante puede pedir la restitución de la cosa cuando quisiere. Mosset, Responsabilidad por daños. Tomo I, 340. 
Por lo tanto, en nuestro concepto, el transporte benévolo se erige en una relación jurídica de naturaleza contractual en la medida en que se comprueben los comentados requisitos precisados por el Código Civil colombiano. Para efectos de la mencionada comprobación es claro que los requisitos 1, 3 y 4 pueden ser constatados con mayor facilidad, mientras que la declaración de voluntad exigida por el artículo 1502 del Código Civil colombiano podría verificarse mediante el análisis de la intención subyacente en la invitación del transportador benévolo y en el consentimiento del transportado.

No obstante, tal como quedó planteado en líneas anteriores, la falta de reconocimiento expreso por parte del ordenamiento jurídico constituiría al transporte benévolo como un contrato atípico, lo que puede erigirse en un contraargumento de su carácter contractual, como en efecto ocurre ${ }^{45}$, a raíz de la ausencia de regulación específica.

En relación con esto, debe mencionarse que tanto la doctrina como la jurisprudencia colombiana han expresado que

[I] as relaciones convencionales que no encajan dentro de ninguno de los tipos reglamentados del contrato, se aprecian por analogía del tipo contractual afín al punto de vista jurídico pertinente, o por los principios generales del derecho de las obligaciones y contratos, y, a título complementario, por el arbitrio judicial ${ }^{46}$.

Con base en lo anterior, el mencionado contraargumento, soportado en la atipicidad del contrato de transporte benévolo, encuentra respuesta en la aplicación de las reglas jurídicamente aceptadas para resolver los vacíos legales. Puntualmente, el contrato atípico de transporte benévolo encontraría, en el contrato típico de transporte oneroso, los elementos legales suficientes para llenar los vacíos puesto que este último es el tipo contractual más próximo.

Como consecuencia de lo anterior, es posible concluir que las obligaciones del contrato de transporte oneroso son predicables del transporte benévolo en cuanto resulten compatibles con la esencia y naturaleza de este último, dentro de las cuales se encuentra la obligación, en cabeza del transportador benévolo, de conducir a las personas y cosas de manera segura. benévolo. Ello por la sencilla razón de que no existe un "contrato de transporte benévolo" y sin contrato, no puede conceptualmente existir responsabilidad contractual". López, "Responsabilidad derivada del transporte benévolo de personas", 533. 


\section{B) Características y elementos del transporte benévolo}

Dada la esencia compartida entre el transporte oneroso y el transporte benévolo respecto de la actividad de conducir personas o cosas de un lugar a otro, muchas de las características y elementos son comunes para las dos categorías.

\section{Características}

Conforme a la estructura del transporte benévolo a partir de la corriente contractualista, se pueden esgrimir una serie de características propias de este tipo de contrato, a saber: innominado, unilateral, principal, consensual y gratuito.

- Innominado: tal como se ha expuesto, la corriente contractualista precisa que el transporte benévolo es un contrato innominado puesto que no es reconocido, ni regulado de manera expresa por el ordenamiento jurídico. Es así, entonces, que la regulación del contrato se encontraría, como se expresó en líneas anteriores, en la analogía con contratos cercanos.

- Unilateral: el contrato de transporte benévolo es un contrato unilateral puesto que, de conformidad con el Código Civil "[...] una de las partes se obliga para con otra que no contrae obligación alguna [...]"47. Lo anterior dado que solo existe la obligación del transportador de conducir al transportado sin que exista en cabeza de este último obligación alguna a favor del transportador.

- Principal: esta característica del contrato de transporte benévolo tiene como efecto la posibilidad de su existencia sin necesidad de acceder a otra convención. Por otro lado, en caso tal de ser accesorio a alguna relación de tipo comercial, será considerado un contrato mercantili ${ }^{48}$.

- Consensual: el contrato de transporte benévolo no requiere formalidad alguna para que exista en el tráfico jurídico puesto que, al ser innominado, la ley no exige la solemnidad para este específico acuerdo de voluntades. Por lo tanto, las partes se encuentran en total libertad para probar la existencia del contrato. 
- Gratuito: además de ser un elemento del transporte benévolo, es una de las características principales de este, puesto que el transportador benévolo no debe recibir contraprestación alguna para que se configure este contrato. De no ser así, estaríamos frente a un contrato de transporte típico, es decir, de los regulados por el código de comercio y código civil.

\section{Elementos del contrato de transporte benévolo ${ }^{49}$}

Así como ocurre en el contrato de transporte oneroso, el transporte benévolo tiene sus elementos propios identificados por la doctrina. Para estos efectos, se acoge la caracterización de los elementos propuestos por Jorge Mosset y Miguel Piedecasas, los cuales serán estudiados a continuación ${ }^{50}$ :

"1) La voluntad de trasladar y ser trasladado [...]": tal como quedó precisado en líneas anteriores, la manifestación de la voluntad de transportar y ser transportado se verifica en la invitación por parte del transportador y la aceptación de la misma por parte del transportado.

"2) que el traslado sea independiente de toda relación jurídica que vincule al transportado con el transportador [...]": en caso de existir una relación comercial subyacente al transporte benévolo, éste cambiaría su naturaleza a un transporte comercial conforme al artículo 995 del Código de Comercio.

"3) el animus beneficendi del transportador [...]": como elemento propio del transporte benévolo, es la beneficencia, liberalidad o cortesía por la cual se realiza la actividad. En este punto, cabe destacar que el transportador benévolo debe estar desprovisto de cualquier tipo de interés, económico o no, en la ejecución del contrato. Lo anterior puesto que "[s]i se ha condicionado el transporte de personas al pago de una suma de dinero, desaparecen los elementos de gratuidad, cortesía y complacencia que tipifican a la relación benévola [...]" ${ }^{\text {"11 }}$.

Marcelo López Mesa establece que, para la existencia del transporte benévolo, se debe verificar “1) Manifestación de voluntad de conductor, dueño, o guardián del vehículo en el sentido de admitir en el mismo a un tercero [...] 2). La razón de la realización del viaje no debe surgir como una necesidad impuesta por una relación jurídica que une a transportador y transportado [...] 3). La aceptación de compartir el viaje por el conductor, dueño o guardián debe ser hecha como un acto de cortesía con el propósito de hacer un favor $[\ldots][y] 4)$. El viajero no debe estar obligado a abonar un precio o efectuar cualquier otra prestación [...]". López, "Responsabilidad derivada del transporte benévolo de personas", 533. 
"4) ausencia de contraprestación por parte del transportado": además, el transporte debe ser totalmente gratuito puesto que al transportador benévolo no le es dable recibir pago alguno, en dinero o en especie, por el servicio prestado puesto que tal pago desnaturalizaría la relación jurídica.

\section{C) La responsabilidad civil surgida del transporte benévolo}

Como consecuencia de la división doctrinal en cuanto a la naturaleza del transporte benévolo, el régimen de responsabilidad civil cambia conforme a cada una de las corrientes comentadas.

Para los partidarios de la corriente anticontractualista, la cual considera al transporte benévolo un hecho sin intención ni virtualidad de obligar al transportador, la responsabilidad civil sería de índole extracontractual. Al respecto, por ejemplo, la Corte Suprema de Justicia de Colombia estableció, en sentencia del 4 de julio de 1957, que "[r]esulta inoperante invocar una responsabilidad contractual en el caso de un transporte benévolo, que solo crea una situación potestativa ya que el conductor complaciente no pretende contraer vínculo jurídico alguno, sino que realiza una atención o mera cortesía"52.

Por lo tanto, entonces, esta corriente doctrinal y jurisprudencial genera, desde el punto de vista procesal, conforme lo afirmado por la Corte Suprema de Justicia en sentencia de 3 de diciembre del 2001, una carga en cabeza de la víctima de tal manera que queda sujeta "a demostrar tanto la existencia del perjuicio como la de la culpa del demandado y el nexo causal entre esos dos factores" 53,54 .

Así mismo, la doctrina que apoya la corriente anticontractualista ha sostenido que la responsabilidad surgida en el transporte benévolo es de índole extracontractual "[...] por no existir no solamente un contrato, sino cualquier vínculo previo a la ocurrencia del daño, y porque el transportador en esas circunstancias, no pretende asumir obligación alguna" 55 .

52 Corte Suprema de Justicia. Sala de Negocios Generales. Sentencia de 4 de julio de 1957. M. P. José Jaramillo.

53 Corte Suprema de Justicia. Sala de Casación Civil. Sentencia de 3 de diciembre del 2001. M. P. Manuel Ardila.

54 Ha establecido la corporación judicial citada que "[c]omprometiéndose la responsabilidad civil extracontractual del transportador benévolo por el acto culposo que ocasiona el daño del pasajero, [...] sería improcedente aplicar la teoría de la culpa presunta [...] en consecuencia, corresponde al perjudicado demostrar dicha culpa para que la acción incoada en esas circunstancias prospere". Corte Suprema de Justicia. Sala de Negocios Generales. Sentencia de 4 de julio de 1957. M. P. José Jaramillo. 
También, es imprescindible resaltar que los defensores de esta corriente fundan su posición, de manera axiológica, en el principio de la equidad, puesto que no es posible juzgar de la misma forma el incumplimiento de la obligación de seguridad $^{56}$ en el transporte realizado a título oneroso, que evaluar la actividad de quien no recibió una contraprestación, es decir, quien actuó de manera altruista. Lo anterior fue expuesto por la Corte Suprema de Justicia que precisó que “[n]o aparece equitativo que quien recibe o solicita un favor se aproveche de él para invocar una responsabilidad presunta de la persona que lo otorga"57.

No obstante lo anterior, aun cuando pareciera inequitativo el tratamiento igualitario de cara al régimen de responsabilidad civil entre quien causa el daño en el contrato de transporte y quien lo hace en las circunstancias del transporte benévolo puesto que aquel recibe una contraprestación y este lo ejecuta por mera cortesía, podría resultar discriminatorio el tratamiento diferenciado entre las víctimas del daño puesto que la onerosidad o gratuidad existente en la relación jurídica no deberían ser considerados factores para agravar o aminorar la carga probatoria de un escenario frente al otro.

Por otro lado, de cara a los efectos de la corriente contractualista, al verse inmiscuida una obligación de seguridad de resultado propia del contrato de transporte, indistintamente de su onerosidad o gratuidad ${ }^{58}$, el acreedor de dicha obligación, es decir, la víctima del daño, no debe probar la culpa del acreedor para reclamar los perjuicios ocasionados por su incumplimiento. Partiendo de la irrelevancia del componente económico en el estudio de la naturaleza jurídica del transporte benévolo, el Consejo de Estado colombiano ha dicho que "no existen razones jurídicas válidas para establecer diferencias en el régimen de responsabilidad por el ejercicio de actividades peligrosas derivado de la mera onerosidad o gratuidad del uso del bien" ${ }^{\prime 59}$. Así mismo, respecto al mismo punto, la Corte Suprema de Justicia puntualizó que "sectores muy autorizados de la doctrina sostienen actualmente que el sistema de culpa probada al que se remite el damnificado en los eventos de

56 A partir de las interpretaciones de la obligación de seguridad en el derecho francés, precisa Prévot, esta se extendió a "[...] aquellas convenciones que de una manera u otra ponían en riesgo la integridad física del acreedor o en los que este tenía una intervención netamente pasiva en la ejecución del contrato [...]". Prévot, La obligación de seguridad, 279.

Corte Suprema de Justicia. Sala de Negocios Generales. Sentencia de 4 de julio de 1957. M. P. José Jaramillo.

"La gratuidad no crea un escudo de protección para el agente dañador; el obrar haciendo algo o dando algo, sin tener en miras la contraprestación, por puro espíritu de generosidad, liberalidad, solidaridad, fraternidad o lo que fuere, no es excusa o eximente liberatorio". Mosset, “¿El transportado gratuitamente viaja a riesgo y ventura? (La asunción o aceptación del riesgo como falacia jurídica)”, 399. 
transporte benévolo o desinteresado, no tiene justificación suficiente en que por el carácter gratuito o de cortesía de la movilización no deba agravarse la responsabilidad del demandado con un sistema de atribución más estricto"60.

Bajo la perspectiva de esta corriente, el acreedor de la obligación de seguridad en el transporte benévolo, entonces, no tendría la carga de la prueba de la negligencia del deudor en la conducta realizada; por el contrario, es este último quien debería demostrar una de las causas extrañas con la finalidad de romper el nexo causal entre el hecho y el daño sufrido por el acreedor $y$, en consecuencia, eximirse de responsabilidad, tal y como pasa en el contrato de transporte oneroso.

A pesar de la aceptación de la corriente contractualista la cual contempla el trato igualitario de los acreedores de la obligación de seguridad en el transporte sin importar su modalidad, compartimos la crítica consistente en que "es tan chocante que el conductor que ha transportado gratuitamente a una persona sea tratado con el mismo rigor que el transportador remunerado, que el mismo se exima de responsabilidad frente al pasajero, si se ha demostrado una grave imprudencia suya"61, puesto que las obligaciones de resultado, como lo es la de seguridad, solo pueden ser desvirtuadas al demostrar una causa extraña, como se precisará en el siguiente apartado.

Para superar la inequidad identificada por el trato igualitario de las víctimas del daño en los supuestos comentados, la propuesta se concentra en la subdivisión de las obligaciones de resultado con la finalidad de atenuar la carga probatoria del deudor de la obligación sin sacrificar las ventajas procesales que se le presentan a la víctima del daño en el marco del transporte benévolo.

\section{Las obligaciones de resultado atenuadas: una solución para el conflicto entre equidad e igualdad en el transporte benévolo}

\section{A) Las obligaciones de resultado y su modernización}

Las obligaciones de resultado, junto con las obligaciones de medio, fueron introducidas y han sido desarrolladas en el ordenamiento jurídico colombiano a través de la jurisprudencia. La Sala de Casación Civil de la Corte Suprema de Justicia, basada 
en la división propuesta por René Demogue, las introdujo, en su sentencia de 30 de noviembre 1935, de la siguiente forma:

[p]ara resolver el primero problema (sic) —el del contenido de la obligación - es menester distinguir entre las obligaciones "determinadas, precisas o de resultado" y las obligaciones "generales de prudencia y diligencia". En las primeras, los actos que el deudor debe ejecutar están estrictamente indicados en el contrato o en la ley supletiva [...]. En las segundas -en las obligaciones generales de prudencia y diligencia - el deudor se ha comprometido a poner solamente toda la diligencia necesaria y a tomar todas las precauciones razonables para llegar a un determinado resultado, que puede no ser alcanzado, a pesar de haber cumplido el deudor con sus deberes de prudencia y diligencia $[\ldots]^{62}$.

Dentro de la misma providencia judicial, la Corte Suprema de Justicia precisó

[...] cuando no se trata de obligación precisa o determinada sino solamente de la obligación general de prudencia y diligencia, los jueces, para determinar la existencia de culpa, tienen que entregarse a un examen de la conducta del demandado, investigar como se ha manejado este, descubrir si hubo de su parte imprudencia o negligencia, y en cambio, cuando la obligación del deudor es precisa o determinada, entonces, en caso de inejecución, la responsabilidad de éste se encuentra necesariamente comprometida con el solo hecho de no haberse alcanzado el resultado, a menos que se pruebe caso fortuito o fuerza mayor o causa extraña, sin que sea procedente ningún examen sobre la conducta del mismo deudor ${ }^{63}$.

Habida cuenta de la dinámica de la vida social, en particular, en los campos científico y tecnológico frente a la lentitud de los procesos legislativos, los jueces, en la valoración de las relaciones jurídicas tienen la imperiosa necesidad de ser coherentes con la nueva realidad y les corresponde por vía jurisprudencial adecuar los efectos de las obligaciones a riesgo de que la administración de justicia quede rezagada frente a los nuevos retos del mundo contemporáneo. $Y$ siempre que se genere desde la ciencia o la tecnología un mayor, profundo y más exacto conocimiento en la realización de una labor, la actualización o modernización de tal actividad inevitablemente suscitará un mayor compromiso entre las partes de la relación jurídica. Los jueces, frente a los avances tecnológicos y científicos, y a partir del manejo y dominio exigidos de ellos en el cumplimiento de las prestaciones 
en las relaciones jurídicas, no han tenido otra alternativa sino la de capotear el temporal echando mano de la aplicación de los principios generales del derecho y, a partir de esa práctica, establecer o determinar responsabilidades y la carga de la prueba del incumplimiento de la prestación de la obligación asumida de acuerdo con su intensidad jurídica. De lo anterior da fe la aplicación de la teoría dinámica de la prueba y del principio res ipsa loquitur, los cuales impactan la actividad probatoria. En el primero de los casos bajo el entendido que el onus probando recae sobre el sujeto que esté en mejores condiciones para aportar la prueba de su afirmación mientras que en el segundo de los casos en la presunción de la culpa por la evidencia fáctica del daño.

De cara a la aplicación del principio de justicia material, el cual se caracteriza por ser aquel que

se opone a la aplicación formal y mecánica de la ley en la definición de una determinada situación jurídica [y que] [e]xige, por el contrario, una preocupación por las consecuencias mismas de la decisión y por la persona que es su destinataria, bajo el entendido de que aquella debe implicar y significar una efectiva concreción de los principios, valores y derechos constitucionales ${ }^{64}$.

El ordenamiento jurídico colombiano, a través de la actividad de los jueces en la resolución de situaciones jurídicas, debe reconfigurar las obligaciones de resultado, especialmente en aquellos casos, como el contrato de transporte benévolo, en el que resulten excesivas las exigencias probatorias en relación con el conjunto de deberes y prerrogativas que se desprenden de la relación jurídica.

Como consecuencia de lo anterior, para efectos de conciliar la equidad y la igualdad en el transporte benévolo frente al tratamiento dado por la analogía planteada respecto del transporte oneroso, propongo adoptar y desarrollar la subcategorización de las obligaciones de resultado que entre ellas distingue las siguientes clases: a) obligaciones de resultado propiamente dichas; b) obligaciones de resultado atenuadas y c) obligaciones de resultado reforzadas, las cuales han sido desarrolladas principalmente en Francia ${ }^{65}$ y Argentina ${ }^{66,67}$, países que tienen un

64 Corte Constitucional. Sentencia T-429 de 1994. M. P. Antonio Barrera Carbonell.

65 Paul-André Crépeau, L'intensité de l'obligation juridique ou des obligations de diligence, de résultat et de garantie (Les Éditions Yvon Blais Inc., 1989).

66 Atilio Aníbal Alterini, "La responsabilidad civil por productos: estado de la cuestión en el derecho argentino", Revista de la Facultad de Derecho y Ciencias Políticas U.P.B., n. ${ }^{89}$, I.

67 En este punto es necesario precisar que, a partir del 2015, en la República Argentina rige un nuevo Código Civil y Comercial adoptado bajo la ley 26994, el cual ha reemplazado al Código Civil de 1869 y al Código de Comercio de 1862. 
sistema jurídico de origen romano-germánico como el de Colombia, y cuyos regímenes de obligaciones y contratos provienen en mayor o menor medida, como el colombiano, del Código Civil de Napoleón de 1804.

El contenido prestacional de las obligaciones de resultado en la subdivisión propuesta es el mismo en cada una de las categorías que la componen, es decir, sin importar su clasificación, ellas hacen referencia a relaciones jurídicas en las que el deber del deudor se contrae a obtener un logro concreto y específico que materializa la satisfacción del acreedor, y, por tanto, son entendidas como "los actos que el deudor debe ejecutar [y que] están estrictamente indicados en el contrato o en la ley supletiva" 68 , razón por la cual existe incumplimiento de la obligación cuando no se consigue el resultado prometido.

Precisado lo anterior, debe indicarse que el impacto en la utilización ${ }^{69}$ de la subclasificación recaerá en los medios de defensa a favor del deudor, con la finalidad de que él pueda eximirse de responsabilidad, sea mediante la prueba de la diligencia debida o a través del rompimiento del nexo causal entre el hecho y el daño. En primer lugar, las obligaciones de resultado propiamente dichas, dentro de la categorización, mantienen las características generales, es decir, el deudor podrá demostrar una de las causas extrañas para eximirse de responsabilidad. Por su parte, las obligaciones de resultado reforzadas ${ }^{70}$ son aquellas en las que se han restringido las causas extrañas que pueden ser usadas como medio de defensa por el deudor incumplido o en las que se les ha dado un grado de calificación especial por parte del legislador. Por último, las obligaciones de resultado atenuadas ${ }^{71}$ no solo mantienen la causa extraña como medio para eximir de responsabilidad al deudor

Corte Suprema de Justicia. Sala de Casación Civil. Sentencia de 30 de noviembre de 1935. M. P. Eduardo Zuleta.

69 Las "[...] obligaciones de resultado ordinarias, agravadas y atenuadas [...] son diferenciaciones en cuanto al contenido de la prueba liberatoria que tiene la carga de procurar el deudor de una obligación de resultado". Atilio Aníbal Alterini y Roberto López, "Carga de la prueba en las obligaciones de medios. (Aplicación a la responsabilidad profesional)", en Doctrinas esenciales: obligaciones y contratos. Doctrinas esenciales. Tomo I, ed./comp. Ricardo Lorenzetti (Buenos Aires: La Ley, 2009), 727.

En cuanto al transporte, es interesante encontrar que en el aéreo, la Corte Suprema de Justicia, citada por Bonivento, ha precisado que "[...] El transportador solo puede exonerarse de culpa demostrando que los daños 'sucedieron por obra exclusiva de terceras personas' o 'por culpa exclusiva del pasajero, o por lesiones orgánicas o enfermedad anterior del mismo que haya sido agravadas a consecuencia de hechos imputables al transportador'”; y c) Aún en los casos en que el daño sea atribuible a las excepciones anteriores, el transportador debe demostrar, adicionalmente, 'que tomó todas las medidas necesarias para evitar el daño o que le fue imposible tomarlas'”. Bonivento, Los principales contratos civiles y comerciales. Tomo II, 198.

71 "En las obligaciones de resultado atenuadas, basta a tal efecto, la demostración de no haber habido culpa. Esto es, la de haber prestado toda la diligencia exigible conforme a la 'naturaleza de la obligación' y 'las circunstancias de las personas, del tiempo y del lugar' [...], sin que sea preciso llegar hasta la frontera de lo imposible". Atilio Aníbal Alterini, "La responsabilidad civil por productos: estado de la cuestión en el derecho argentino", Revista Facultad de Derecho y Ciencias Políticas, n. 89, I (1990): 131. 
incumplido, sino que amplían la referida defensa a la prueba de una conducta diligente y cuidadosa en la ejecución de la actividad. Esta última sería la propuesta para llegar a la solución del problema planteado en relación con el transporte benévolo.

\section{B) Las obligaciones de resultado atenuadas en el contrato de transporte benévolo}

Una vez decantadas las razones por las cuales el transporte benévolo debería revestir la calidad de contrato y expuestas las críticas y conflictos de cara a la aplicación del régimen jurídico propio del transporte oneroso y, por supuesto, afirmado el carácter de resultado de las obligaciones que de este último emanan, se debe entrar a plantear la solución que se propone frente a las críticas y dificultades que se desprenden de la inequidad existente en el trato que se da a quien presta un servicio de transporte, frente a la obligación de conducir sanos y salvos a las personas y cosas. Lo anterior, dado que resultaría inequitativo mantener, en cuanto a la obligación comentada se refiere, la misma severidad probatoria para quien recibe remuneración por el mencionado servicio de transportar, como para quien, sin recibir contraprestación alguna y bajo la óptica de la cortesía, realiza la misma actividad.

Precisado lo anterior debemos destacar, tal como quedó precisado en líneas anteriores, que las obligaciones de resultado atenuadas se caracterizan porque en ellas, además de las causas extrañas propias del derecho civil, el deudor puede eximirse mediante "[...] la demostración de no haber habido culpa. Esto es, la de haber prestado toda la diligencia exigible conforme a la "naturaleza de la obligación" y "las circunstancias de las personas, del tiempo y del lugar" [...], sin que sea preciso llegar hasta la frontera de lo imposible"72.

Dicha conceptualización de las obligaciones se constituye en una garantía para la víctima del daño y en un alivio procesal para el transportador benévolo puesto que la primera tendrá que probar únicamente la insatisfacción del interés jurídico inmerso en la obligación y el daño sufrido, mientras que a los segundos, es decir, a los transportadores benévolos, se les extienden los medios de defensa frente a la demanda de responsabilidad civil por los perjuicios ocasionados, dado que pueden hacer uso de cualquiera de las causas extrañas para romper el nexo de causalidad, así como probar la debida diligencia y prudencia con la finalidad de eximirse de responsabilidad. 
El mencionado alivio procesal tiene como fundamento principal la salvaguarda de la igualdad entre las víctimas de daños ocasionados por la actividad del transporte, sin importar su onerosidad o gratuidad, y la equidad en cuanto al tratamiento preferencial que se le da al transportador benévolo respecto de los medios de defensa se refiere.

La base del planteamiento que realizamos está, en primer lugar, en que no se encuentra razón, más allá de la onerosidad propia del contrato de transporte típico, para hacer diferenciación entre las víctimas en el transporte oneroso y en el benévolo. Por lo tanto, fundamentar el trato diferenciado que supone la aplicación de un régimen probatorio distinto en el beneficio económico reportado a una de las partes, resulta, por lo menos, debatible en un contexto jurídico en el que impera el principio favor victimae ${ }^{73}$, dado que el hecho generador del daño es igual en ambos supuestos, es decir, el incumplimiento de una obligación de idénticas características.

Para resolver el problema planteado, debemos acudir al artículo 8 de la Ley 153 de $1887^{74}$ el cual establece que "[c]uando no hay ley exactamente aplicable al caso controvertido, se aplicarán las leyes que regulen casos o materias semejantes, y en su defecto, la doctrina constitucional y las reglas generales de derecho", específicamente haciendo uso de los principios generales de derecho.

La adopción de las obligaciones de resultado atenuadas encontraría sustento jurídico en el estudio de los principios de protección a la víctima en concordancia con el principio de solidaridad, los cuales deben ser articulados por el principio de justicia contractual que permite que, al deudor, bajo ciertas circunstancias, se le dé un trato más favorable ${ }^{75}$.

En efecto, el contexto jurídico colombiano ha venido siendo permeado por el principio de protección a la víctima. Este principio puede ser definido, desde la perspectiva civil, como aquel

conforme al cual las dudas que puedan surgir a la hora de establecer la dimensión de la reparación han de resolverse en beneficio de quien injustamente sufrió el daño, por cuanto una definición contraria a la acabada de señalar restringiría, sin motivo racional alguno y en detrimento de aquel, sus posibilidades indemnizatorias ${ }^{76}$.

Arturo Solarte Rodríguez, "El principio favor victimae y su aplicación en el derecho colombiano", Anuario de Derecho Privado, 1 (2019): 257-304. DOI: http://dx.doi.org/10.15425/2017.205

74 Corte Constitucional. Sentencia C-083 de1995. M. P. Carlos Gaviria.

75 Corte Constitucional. Sentencia C-1008 del 2010. M. P. Luis Ernesto Vargas.

76 Corte Suprema de Justicia. Sala de Casación Civil. Sentencia del 15 de abril del 2009. M. P. César Julio Valencia Copete. 
Como efecto de la aplicación de este principio, se le debe conceder la ventaja procesal a la víctima frente a la exención de la prueba de la culpa del deudor para la reclamación de los perjuicios sufridos con ocasión del daño, puesto que no existe justificación alguna para que una obligación de idénticas características en ambos escenarios sea tratada de manera distinta.

Sin embargo, el reconocimiento de la obligación de resultado en cabeza del transportador benévolo se constituiría en un desincentivo para los actos desinteresados de colaboración, como el que se encuentra en la base del transporte benévolo, los cuales encuentran sustento constitucional en el principio y deber de solidaridad que es definido como "la vinculación del propio esfuerzo y actividad en beneficio o apoyo de otros asociados"77.

Con la finalidad de articular la protección especial a la víctima y el deber de solidaridad, pilar fundamental de un Estado social de derecho como lo es Colombia, los jueces deberían, en virtud del principio de justicia contractual, hacer el reconocimiento de las obligaciones de resultado atenuadas, las cuales tendrían como propósito otorgar la ventaja procesal a favor de la víctima y conceder, sin sacrificar la esencia de la obligación inmersa en el contrato de transporte benévolo, alguna facilidad al transportador benévolo para que pueda ejercer su defensa en un eventual proceso de responsabilidad civil. Al respecto, debemos puntualizar que el principio de justicia contractual tiene como finalidad evitar que se socave "el equilibrio prestacional que, en línea de principio, debe existir en todo contrato"78.

Es así que la mejor prerrogativa consistiría en extender los medios de defensa de este tipo de transportador. Por ello, se debe considerar que, a pesar de que la obligación de conducir a las personas de manera segura reviste la naturaleza jurídica de obligación de resultado, la prueba de diligencia y prudencia en la ejecución de la obligación pueda ser considerada suficiente para exonerar de responsabilidad a quien ejerce el transporte en esos términos.

Dicha posición, por supuesto basada en un fundamento axiológico en torno a los principios de igualdad entre las víctimas y de justicia y equidad para justificar el trato diferenciado entre los transportadores, surgiría de la mano de la aceptación de las obligaciones de resultado atenuadas en el derecho colombiano, tal como se ha aceptado en otras latitudes. 


\section{Conclusiones}

Agotado el estudio del transporte benévolo y las obligaciones de resultado atenuadas como propuesta para resolver el conflicto entre igualdad y equidad detectado bajo la óptica contractualista, se presentan las siguientes conclusiones:

1. El transporte benévolo debe ser considerado un contrato atípico puesto que concurren en su nacimiento jurídico los elementos establecidos en el Código Civil de Colombia.

2. Dada la atipicidad del contrato de transporte benévolo, se debe acudir a las normas del contrato de transporte oneroso para hallar su regulación, puesto que es el tipo contractual más cercano en cuanto a las obligaciones.

3. Dentro del estudio analógico comentado, se debe determinar el contenido de la prestación debida del transportador al transportado y en tal virtud se concluye que en el contrato de transporte benévolo surge para el transportador una obligación de resultado.

4. El carácter de resultado de la obligación de transportar de manera sana y salva en cabeza del transportador benévolo presenta varios efectos. El primero es que da una protección mayor a la víctima del daño puesto que solo debe probar el incumplimiento de la obligación, el nexo de causalidad y el daño sufrido. El segundo efecto se centra en la injusticia de dar los mismos medios de defensa tanto al transportador oneroso como al transportador benévolo, a pesar de que aquel, contrario a lo que le sucede a este, recibe una contraprestación por sus servicios.

5. Con la finalidad de solucionar el enfrentamiento entre el principio de igualdad visto desde la protección de las víctimas del daño surgido con ocasión del transporte benévolo, y el principio de equidad y solidaridad dado que mal podría tratarse de igual manera a dos personas que tienen una posición jurídica distinta como en el caso de los transportadores mencionados, se propone acoger la categorización de las obligaciones de resultado atenuadas.

6. Las obligaciones de resultado atenuadas pueden ser definidas como aquellas en las cuales el deudor garantiza la obtención de un resultado pactado y, en caso de incumplimiento, este tiene la posibilidad, además de acudir a una causa extraña, de hacer uso de la prueba de la debida diligencia para efectos de liberarse de responsabilidad civil por el incumplimiento. 
7. Haciendo uso de esta modalidad, las víctimas del transporte benévolo y del transporte oneroso pueden ser tratadas en forma igual, los transportadores benévolos y onerosos de manera distinta y así se preserva la obligación de resultado de transportar de manera segura, que es común a los dos contratos.

\section{Referencias}

Acuña Anzorena, Arturo. "Transporte gratuito y responsabilidad en caso de accidente". En Responsabilidad civil. Doctrinas esenciales (parte especial) Tomo IV, compilado por Félix Trigo, 209-350. Buenos Aires: La Ley, 2007.

Alessandri Rodríguez, Arturo. Derecho civil de los contratos. Santiago de Chile: Ediciones Zamorano y Caperan, 1976.

Alterini, Atilio Aníbal. "La responsabilidad civil por productos: Estado de la cuestión en el derecho argentino". Revista Facultad de Derecho y Ciencias Políticas, n. ${ }^{\circ}$ 89, I (1990): 100-131.

Alterini, Atilio Aníbal y Roberto López. "Carga de la prueba en las obligaciones de medios. (Aplicación a la responsabilidad profesional)". En Doctrinas esenciales: obligaciones y contratos. Doctrinas esenciales. Tomo I. Compilado por Ricardo Lorenzetti, 700-750. Buenos Aires: La Ley, 2009.

Arrubla Paucar, Jaime Alberto. Contratos mercantiles. Bogotá: Ediciones Dike, 1988.

Bonivento Fernández, José Alejandro. Los principales contratos civiles y comerciales. Tomo II. Bogotá: Ediciones Librería del profesional, 1991.

Bustamante Alsina, Jorge. Teoría general de la responsabilidad civil. Buenos Aires: Abeledo-Perrot, 1983.

Cabanillas Sánchez, Antonio. Las obligaciones de actividad y de resultado. Barcelona: Ediciones José María Bosch, 1993.

Corte Constitucional. Sentencia T-429 de 1994. M. P. Antonio Barrera Carbonell.

Corte Constitucional. Sentencia C-083 de 1995. M. P. Carlos Gaviria.

Corte Constitucional. Sentencia C-529 del 2010. M. P. Mauricio González.

Corte Constitucional. Sentencia C-1008 del 2010. M. P. Luis Ernesto Vargas. 
Corte Suprema de Justicia. Sala de Casación Civil. Sentencia de 30 de noviembre de 1935. M. P. Eduardo Zuleta.

Corte Suprema de Justicia. Sala de Negocios Generales. Sentencia de 11 de febrero de 1946. M. P. Eleuterio Serna.

Corte Suprema de Justicia. Sala de Negocios Generales. Sentencia de 4 de julio de 1957. M. P. José Jaramillo.

Corte Suprema de Justicia. Sala de Casación Civil. Sentencia de 2 de febrero del del 2001. M. P. Carlos Esteban Jaramillo Schloss.

Corte Suprema de Justicia. Sala de Casación Civil. Sentencia de 3 de diciembre del 2001. M. P. Manuel Ardila.

Corte Suprema de Justicia. Sala de Casación Civil. Sentencia del 15 de abril del 2009. M. P. César Julio Valencia Copete.

Corte Suprema de Justicia. Sala de Casación Civil. Sentencia de 16 de diciembre del 2010. M. P. Arturo Solarte Rodríguez.

Corte Suprema de Justicia. Sala de Casación Civil. Sentencia de 6 de diciembre del 2011. M. P. Arturo Solarte Rodríguez.

Consejo de Estado. Sala de lo Contencioso Administrativo. Sección Tercera. Sentencia de 25 de marzo de 1999. C. P. Ricardo Hoyos Duque.

Crépeau, Paul-André. L'intensité de l'obligation juridique ou des obligations de diligence, de résultat et de garantie. Les Éditions Yvon Blais Inc., 1989.

Decreto 410 de 1971, del 27 de marzo. Código de Comercio de la República de Colombia. Artículo 981. Diario Oficial n. ${ }^{\circ} 33339$.

Demogue, René. Traité des Obligations en Général, Tomo V. París: Librairie Arthur Rousseau et Cie., 14, Rue Soufflot, 14, 1925

Ley 84 de 1873, del 26 de mayo. Código Civil de la República de Colombia. Artículo 2070. Diario Oficialn. ${ }^{\circ} 2867$.

López Mesa, Marcelo. “Responsabilidad derivada del transporte benévolo de personas". En Tratado de responsabilidad civil, tomo IV. Compilado por Félix Trigo y Marcelo López. 495-533. Buenos Aires: La Ley, 2011.

Mosset, Jorge y Miguel Piedecasas. Accidentes de tránsito. Buenos Aires: Rubinzal Culzoni, 2009.

Ospina Fernández, Guillermo. Régimen general de las obligaciones. Bogotá: Temis, 1978.

Ospina Fernández, Guillermo y Eduardo Ospina Acosta. Teoría general del contrato y del negocio jurídico. Bogotá: Ediciones Temis, 2005. 
Prévot, Juan Manuel. La obligación de seguridad. Bogotá: Ediciones Temis, 2012.

Santos Ballesteros, Jorge. Instituciones de responsabilidad civil. Tomo II. Bogotá: Javegraf, 2007.

Solarte Rodríguez, Arturo. "La buena fe contractual y los deberes secundaros de conducta”. Universitas 53, n.0 108 (2004): 281-315. https:// revistas.javeriana.edu.co/index.php/vnijuri/article/view/14730

Solarte Rodríguez, Arturo. "El principio favor victimae y su aplicación en el derecho colombiano". Anuario de Derecho Privado 1 (2019): 257-304. http://dx.doi.org/10.15425/2017.205

Tamayo Jaramillo, Javier. Tratado de responsabilidad civil. Bogotá: Legis, 1986. 